\title{
Effects of the photobiomodulation using different energy densities on the periodontal tissues under orthodontic force in rats with type 2 diabetes mellitus
}

\author{
Mônica Fernandes GOMES(a) \\ Maria da Graças Vilela \\ GOULART $^{\text {(a) }}$ \\ Lilian Chrystiane GIANNASI (a) \\ Cybelle Mori HIRAOKA(a) \\ Gabriela de Fátima Santana \\ MELO(a) \\ Renato Amaro ZANGARO(b) \\ Celestino José Prudente \\ NÓBREGA(c) \\ Miguel Angel Castillo SALGADO(a)
}

(a) Universidade do Estado de São Paulo -

Unesp, Institute of Science and Technology, Center of Biosciences Applied to Patients with Special Health Care Needs, São Jose dos Campos Campus, SP, Brazil.

(b)Biomedical Engineering Center, Anhembi Morumbi University - UAM, São José dos Campos, São Paulo, SP, Brazil.

(c)Department of Orthodontics, Case Western Reserve University, Cleveland, OH, USA.

Declaration of Interest: The authors certify that they have no commercial or associative interest that represents a conflict of interest in connection with the manuscript.

Corresponding Author: Mônica Fernandes Gomes E-mail:mfgomes@ict.unesp.br

hitps://doi.org/10.1590/1807-3107bor-2018.vol32.0061

Submitted: April 12, 2017

Accepted for publication: May 14, 2018

Last revision: May 21, 2018
Abstract: To evaluate the impact of the GaAlAs diode laser with energy densities of $160 \mathrm{~J} / \mathrm{cm}^{2}, 320 \mathrm{~J} / \mathrm{cm}^{2}$, and $640 \mathrm{~J} / \mathrm{cm}^{2}$ on the periodontal tissues under continuous orthodontic force application and on the rate of orthodontic tooth movement in rats with type-2 diabetes mellitus. The intensity of primary alveolar bone formation was also investigated through the immune-positive osteocytes for OPN antibody. Forty adult male Wistar rats were divided into eight groups of 5 rats: normoglycemic (N), 160 J-laser-normoglycemic (160 J-LN), 320 J-laser-normoglycemic (320 J-LN), 640 J-laser-normoglycemic (640 J-LN), diabetic (D), 160 J-laser-diabetic (160 J-LD), 320 J-laser-diabetic (320 J-LD), and 640 J-laser-diabetic (640 J-LD) rats. Diabetes mellitus was induced by a single intravenous injection of 40 $\mathrm{mg} / \mathrm{kg}$ monohydrated-alloxan. An orthodontic force magnitude of $20 \mathrm{cN}$ was applied. The laser parameters were continuous emission of $780-\mathrm{nm}$ wavelength, output power of $20 \mathrm{~mW}$, and fiber probe with a spot size of $0.04 \mathrm{~cm}$ in diameter. Radiographic, histomorphological, and immunohistochemical analysis were performed after a period of 21 days. The photobiomodulation using the energy density of $640 \mathrm{~J} / \mathrm{cm}^{2}$ strongly stimulated the alveolar bone formation and contributed the reorganization of the soft periodontal tissues, followed by the $320 \mathrm{~J} / \mathrm{cm}^{2}$. Extensive alveolar bone loss, intense infiltration of inflammatory cells, and degradation of the PDJ tissue were mainly found in the $\mathrm{D}$ and $160 \mathrm{~J}-\mathrm{LD}$ groups. The rate of orthodontic tooth movement was represented by the interdental distance between the cementoenamel junctions of the right mandibular first and second molars. This distance was larger in the diabetic groups (D: 39.98 $\pm 1.97,160 \mathrm{~J}-\mathrm{LD}$ : 34.84 \pm 6.01 , $320 \mathrm{~J}-\mathrm{LD}$ : $29.82 \pm 1.73$, and $640 \mathrm{~J}-\mathrm{LD}: 35.47 \pm 4.56)$ than in the normoglycemic groups $(\mathrm{N}$ : 21.13 $\pm 1.19 ; 160$ J-LN: $22.69 \pm 0.72,320$ J-LN: 22.28 \pm 0.78 , and 640 J-LN: 24.56 \pm 2.11$)$. The number of osteopontin-positive osteocytes was significantly greater in the 640 J-LD $(14.72 \pm 0.82 ; \mathrm{p}<0.01)$ and $640 \mathrm{~J}-\mathrm{LN}(13.62 \pm 1.33 ; \mathrm{p}<0.05)$ groups than with D $(9.82 \pm 1.17)$ and $160 \mathrm{~J}-\mathrm{LD}(9.77 \pm 1.10)$ groups. Therefore, the energy density of $640 \mathrm{~J} / \mathrm{cm}^{2}$ provided the best maintenance and integrity of the periodontal tissue microarchitecture under continuous orthodontic force when compared with the other dosages, mainly in the uncontrolled diabetic rats. The interdental distance was greater in the $\mathrm{D}$ and $160 \mathrm{~J}-\mathrm{LD}$ groups due to presence of severe periodontitis caused by diabetes plus the mechanical stress generated by continuous orthodontic forces, implying, thus, an insufficient biostimulatory effect for the dosage of $160 \mathrm{~J} / \mathrm{cm}^{2}$.

Keywords: Diabetes Mellitus, Type 2; Orthodontics; Low-level Laser therapy; Periodontal; Guided Tissue Regeneration, Periodontal; Osteopontin. 
Effects of the photobiomodulation using different energy densities on the periodontal tissues under orthodontic force in rats with type 2 diabetes mellitus

\section{Introduction}

Diabetes Mellitus (DM) is a chronic metabolic disorder characterized by a defect either in the secretion or in the action of insulin, or both, leading to chronic hyperglycaemia and disturbances of carbohydrate, fat and protein metabolism. ${ }^{1,2}$ Hyperglycaemia over a long period results in various classic complications, including periodontopathy. ${ }^{1,3,4,5,6}$ Several studies have demonstrated significant alterations to bone and mineral metabolism, which are related to the following factors: decrease of osteoclasts and osteoblasts, enhance of apoptosis of osteoblasts, and reduces osteocalcin synthesis. These processes lead to extensive bone loss and, as a consequence, impaired bone turnover and formation. ${ }^{3,6,7,8}$ Alternative therapies have been proposed to stimulate alveolar bone remodeling and to favor a better response in gingival and periodontal ligament tissues, especially in the supported treatments for orthodontics. In particular, the photobiomodulation (PBM), previously known as low-level laser therapy (LLLT), has showed great effectiveness due to its analgesic, anti-inflammatory and photobiostimulatory properties, resulting in a faster tooth movement with no periodontal tissue side effects. $9,10,11,12,13,14,15,16,17$ However, one of the key issues is to find an appropriate energy density for different experimental and clinical trials.

Based on these investigations, the purpose of this study was to evaluate the impact of the GaAlAs diode laser using the energy densities of $160 \mathrm{~J} / \mathrm{cm}^{2}, 320 \mathrm{~J} / \mathrm{cm}^{2}$, and $640 \mathrm{~J} / \mathrm{cm}^{2}$ on the periodontal tissues under continuous orthodontic compression and tension in normoglycemic and diabetic rats through the histomorphological analysis. The rate of orthodontic tooth movement, represented by the interdental distance between the cementoenamel junctions of the right mandibular first and second molars, and the intensity of alveolar bone formation were also assessed through digital radiographic images and immunohistochemical analysis using antibody for OPN (osteopontin), respectively.

\section{Methodology}

\section{Animals}

Forty healthy adult male Wistar rats, between 90 and 100 days and an average body weight of 200-250g, were randomly selected and submitted to orthodontic tooth movement. They were divided into eight groups of 5 rats: normoglycemic (N), 160 J-laser-normoglycemic (160 J-LN), 320 J-laser-normoglycemic (320 J-LN), 640 J-lasernormoglycemic (640 J-LN), diabetic (D), 160 J-laser-diabetic (160 J-LD), 320 J-laser-diabetic (320 J-LD), and 640 J-laser-diabetic (640 J-LD) rats. Subsequently, they were placed under natural lighting in ambient temperature conditions, fed a standard commercial diet, and given water ad libitum. This research was approved by the Animal Experimentation Ethics Committee of the Institute of Science and Technology-Campus São José dos Campos/UNESP (protocol No. 11/2011-PA/Ethics in Research Committee). This work is in accordance with guidelines approved by the Council of the American Psychological Society (2010) for the use of animal experiments. All applicable international, national, and/or institutional guidelines for the care and use of animals were followed.

\section{Alloxan-induced diabetes model}

Initially, the animals were anesthetized with ketamine (5 mg/kg; Dopalen ${ }^{\circledR}$; Agribrands, São Paulo, Brazil) and xylazine $\left(10 \mathrm{mg} / \mathrm{kg}\right.$; Anasedan ${ }^{\circledR}$; Agribrands, São Paulo, Brazil) solution, via intraperitoneal route, prior to inducing diabetes and applying the orthodontic apparatus. After, they received a single intraperitoneal injection of $40 \mathrm{mg} / \mathrm{kg}$ monohydrated alloxan (Sigma-Aldrich, St. Louis, MO, USA), dissolved in $5 \mathrm{~mL}$ of $\mathrm{NaCl}(0.15$ $\mathrm{mol} / \mathrm{L}$ ) through the penile vein. Hyperglycaemia was indicated when the blood glucose level rose above $200 \mathrm{mg} / \mathrm{dL}$. From blood samples of the tail vein, the hyperglycaemia level was verified at 7 days after alloxan injection, during the application of the laser irradiation, and before euthanasia of the animals; whereas, in diabetic rats submitted to no irradiation, the hyperglycaemia level was assessed at 7 days after alloxan injection and during threeday intervals until the euthanasia of them. The obtained values of the blood glucose levels were above $200 \mathrm{mg} / \mathrm{dL}$; however, some rats exhibited the values greater than $500 \mathrm{mg} / \mathrm{dL}$. The diagnosis of diabetes was, then, confirmed. ${ }^{17}$ 


\section{Installation of orthodontic appliance}

The orthodontic appliance was installed 7 days after diabetes was confirmed. The anesthetized rats were placed in the dorsal decubitus position, with the four limbs affixed to a surgical table. Additionally, two adapted mouth openers were developed, with stainless steel wire of round section $0.8 \mathrm{~mm}$ in diameter, to allow the full visualization of intrabuccal structures and to inhibit any forward movement of the head. After these procedures, an adapted orthodontic appliance, composed of a 4.0-mm NiTi closed coil spring (Morelli® Campinas, São Paulo, Brazil), was attached to the animals. This spring was installed around the right mandibular first molar and stretched until the right mandibular central incisor above the level of the gingiva, applying a force magnitude of $20 \mathrm{cN}$ (Figure 1). This apparatus was fixed over the mandibular central incisor surface with lightcured composite resin (Quick Cure, Reliance Orthodontic Products, Itasca, USA). ${ }^{17}$

\section{Photobiomodulation}

A GaAlAs diode laser (Twin Flex II, MMOptics, São Paulo, Brazil) with a continuous emission of a $780 \mathrm{~nm}$ wavelength, an output power of $20 \mathrm{~mW}$, and a fiber probe with a spot size of $0.04 \mathrm{~cm}$ in diameter and an area of $0.00126 \mathrm{~cm}^{2}$ were used. Without movement, the tip was held perpendicular and in contact with the alveolar mucosa. This procedure was done by a single operator. The root surface of the right mandibular first molar was irradiated at one point, located in the middle third of the root, on alternating days during 21 days until the euthanasia of the animals. For this study, the energy densities of $160 \mathrm{~J} / \mathrm{cm}^{2}, 320 \mathrm{~J} / \mathrm{cm}^{2}$ and $640 \mathrm{~J} / \mathrm{cm}^{2}$ were applied in an exposition time of $10 \mathrm{~s}, 20 \mathrm{~s}$ and 40 $\mathrm{s}$, respectively, to the normoglycemic and diabetic rats. Each animal received a total of 10 doses of laser radiation. The calculation of the fluence was evaluated with the following formula: energy density $\left(\mathrm{J} / \mathrm{cm}^{2}\right)=$ (outputpower (w) x exposition time (s)) / spot size area $\left(\mathrm{cm}^{2}\right)$.

\section{Radiological parameter}

To measure the interdental distance between the cementoenamel junctions of the right mandibular first and second molars which represents the rate of orthodontic tooth movement, the digital radiographic images of the hemimandibles were taken only at the end of the experiment through an X-ray apparatus (Gendex 765DC, Gendex Dental Systems, Milan, Italy) and a sensor-type image plate (charge-coupled device; Trophy Radiologie, Vincennes, France), with an active area of $600 \mathrm{~mm}^{2}$. The radiographs were exposed at a fixed focal distance (ffd) of $40 \mathrm{~cm}$, settings of $7 \mathrm{~mA}$ and $65 \mathrm{KV}$, and an exposition

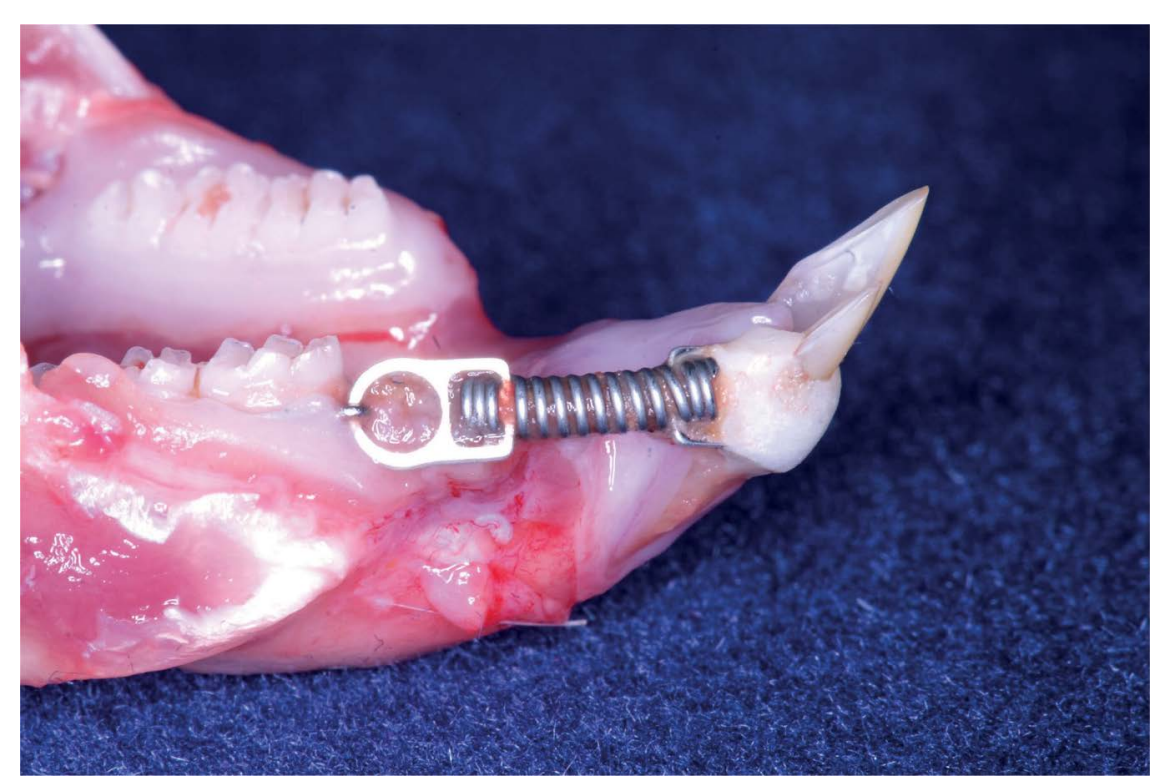

Figure 1. Orthodontic appliance, composed of a 4.0-mm NiTi closed coil spring, installed between the right mandibular first molar and right mandibular central incisor. 
Effects of the photobiomodulation using different energy densities on the periodontal tissues under orthodontic force in rats with type 2 diabetes mellitus

time of 0.04 seconds. The sensor plate images were read by the program Visualix 2.0 (Gendex Dental Systems, Milan, Italy) and these images were transferred to a computer. The interdental distance was measured by the software Adobe Photoshop CS3 Extended (Adobe Systems Inc., San Jose, CA, USA).

The width value $(\mathrm{W})$ varied, but the angulation (A) and height values $(\mathrm{H})$ were maintained at zero degrees, ensuring the fidelity of linear measurements. The $W$ value was given in pixels. The values of the horizontal ( $\mathrm{x}$ ) and vertical (y) axes of the image were 595.50 pixels $(30 \mathrm{~mm})$ and 412.50 pixels $(20 \mathrm{~mm})$, respectively (Figure 2). The conversion between the width and the pixel number of the image is: 1 pixel $=0.05 \mathrm{~mm}$. Five width values for each animal were measured by two trained observers on three occasions at five-day intervals, in order to minimize the influence of observer memory; the average value was then used in the statistical analysis.

\section{Histology}

Five anesthetized animals in each group were euthanized at just a time interval of 21 days after the installation of the orthodontic appliance and the PBM application. The hemimandible that contained the orthodontically was fixed in a $4 \%$ buffered paraformaldehyde solution (Sigma-Aldrich Chemical, St. Louis, MO, USA) for $48 \mathrm{~h}$, decalcified in a 10\% EDTA aqueous solution (Sigma-Aldrich Chemical, St. Louis, MO, USA) at room temperature and constant blend, then processed, and embedded in paraffin. Histological sections were cut to a thickness of $3 \mu \mathrm{m}$ and in parallel to longitudinal axis of the moved tooth in the frontal plan for histomorphological (staning with hematoxylineosin) and immunohistochemical analysis.

\section{Immunohistochemistry}

For immunohistochemical analysis, slices were placed on silane-coated glass slides. The amplification labeled streptavidin-biotin (LSAB) method was used for the following rat monoclonal antibodies: antiOPN (osteopontin, code: LF-175, National Institute of Dental and Craniofacial Research [NIDCR]) to evaluate the intensity of primary bone tissue formation. The antigenic retrieval was performed in a $0.1 \mathrm{M}$ Tris buffer for anti-OPN antibody using a microwave. The negative control was obtained from histological sections with no primary antibody for anti-OPN. The area of the right mandibular first molar was delimited using a drawing tool in the 4.7.2 Axiovision program

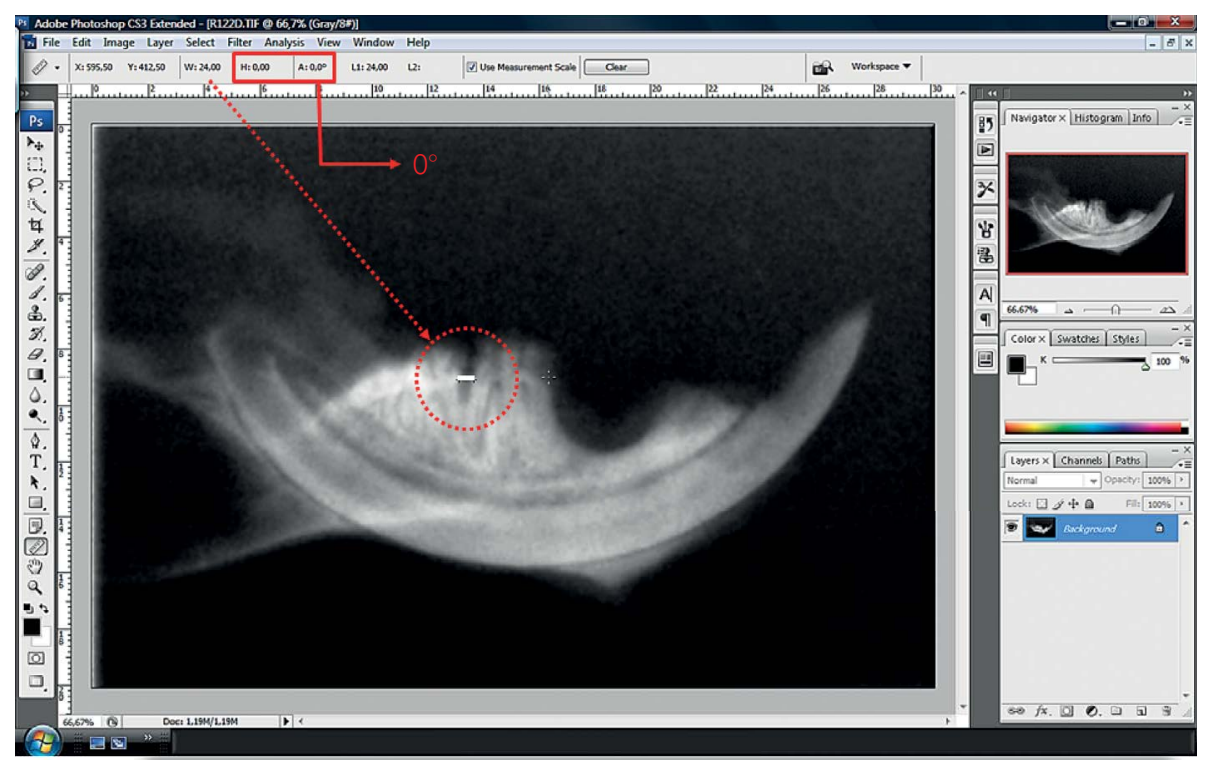

Figure 2. Rate of tooth movement is represented by the interdental distance between the cementoenamel junctions of right mandibular first and second molars (dotted arrow), which is indicated by the width value $(W)$ and zero degrees of angulation $(A)$ and height $(H)$. The values of the horizontal $(x)$ and vertical $(y)$ axes of the image are 595.50 pixels $(30 \mathrm{~mm})$ and 412.50 pixels $(20 \mathrm{~mm})$, respectively. 
(Carl Zeiss Vision Imaging Systems, Oberkochen, Germany). The images were taken using a x40 / 0.65 objective lens (ACHROPLAN, Carl Zeiss) and an ocular x10 (W-PI, Carl Zeiss) in a light microscope (Axioskop 40; Carl Zeiss) with a coupled digital camera (AxioCam MRc5, Carl Zeiss). The counting of immune-positive osteocytes for OPN antibody inside the newly formed alveolar bone tissue was accomplished in five random histological fields. These fields were located at the mesial surface of the interdental septum (between the right mandibular second and first molars) and mandibular first molar furcation. Subsequently, a mean value was calculated.

The sequential timing of the experimental steps performed in each studied group is illustrated in Figure 3.

\section{Statistical Analysis}

The medium values of the quantitative results were compared among the eight groups through the analysis of variance (one-way ANOVA) and the Tukey test (GraphPad InStat software version 5.0 for Windows 7, San Diego, CA, USA). The level of significance was set at $\mathrm{p}<0.05$. Then, the test power was done for linear measure and histomorphometry analyses, using Minitab software version 17.1.0 (Minitab Inc., State College, PA, USA). Standard deviation of 16 units for linear measure and 5 units for histomorphometry showed a difference of 50 and 20 units, respectively. From these values, five animals per group were deemed necessary for the observation period of 21 days in order to attain $80 \%$ test power.

\section{Results}

\section{Histomorphological analysis}

The analyzed areas were gingival epithelium (oral gingival, sulcular, and junctional epitheliums), lamina propria (connective tissue), periodontal ligament (PDL), and alveolar bone, especially in the furcation and interdental regions; additionally, the presence of tooth root resorption or the lack thereof was investigated. These structures were examined after the PBM with different energy densities in the normoglycemic and diabetic groups.

Regarding the normoglycemic groups, the $\mathrm{N}$ and $160 \mathrm{~J}-\mathrm{LN}$ group exhibited intense resorption throughout the laminate alveolar bone, followed by the $320 \mathrm{~J}-\mathrm{LN}$ group. Considering the tooth supporting tissues, alveolar bone tissue was replaced by a osteogenic connective tissue composed of numerous osteogenic cells and news osteoblasts, abundant blood capillaries, and osteoid matrix, especially in the $160 \mathrm{~J}-\mathrm{LN}$ group, at the mandibular first molar furcation region. At the interdental region where the gingival surface showed no epithelial covering, serous-fibrinous pseudomembrane over the ulcerated surface, granulation tissue, and extensive alveolar bone losses were found. On the other hand, some specimens displayed hyperplastic junctional and gingival epithelia with their crests elongated and interconnected between them, infiltration of inflammatory cells, and moderate alveolar bone loss

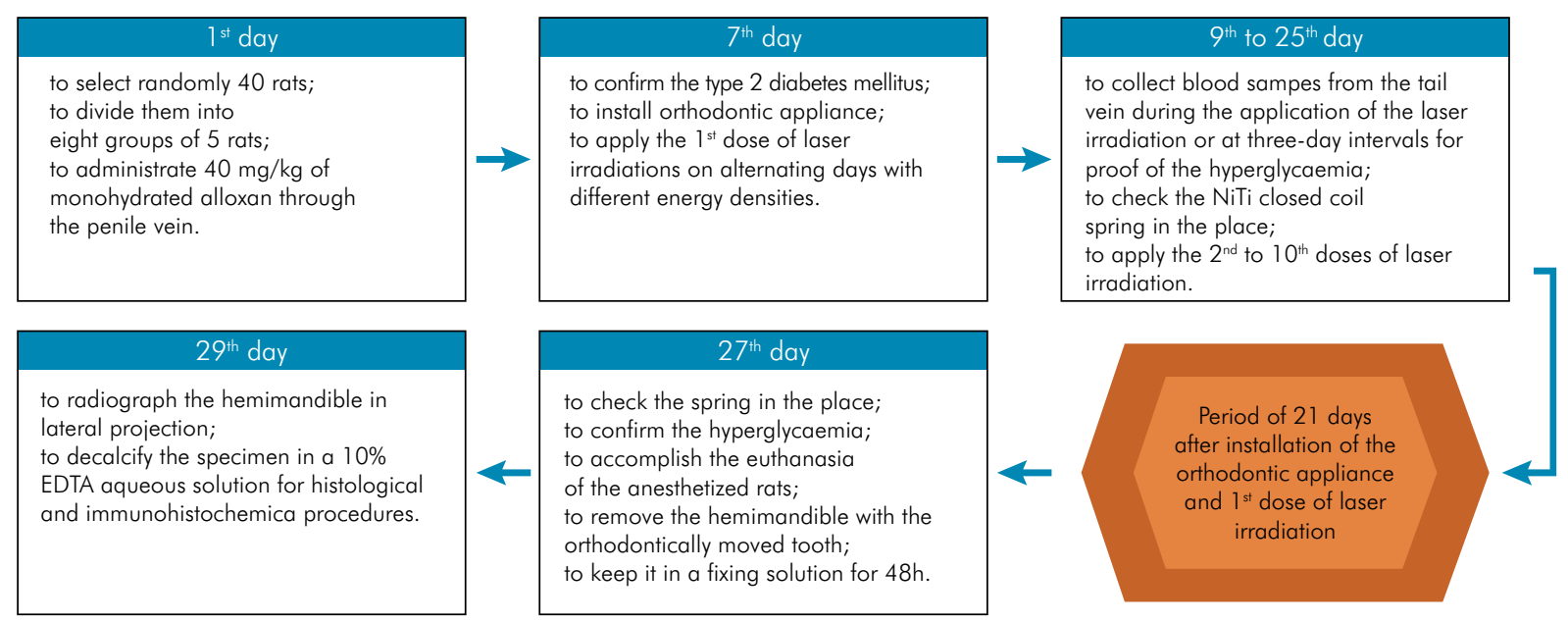

Figure 3. Flowchart showing the sequential timing of the experimental steps for each studied group. 
Effects of the photobiomodulation using different energy densities on the periodontal tissues under orthodontic force in rats with type 2 diabetes mellitus

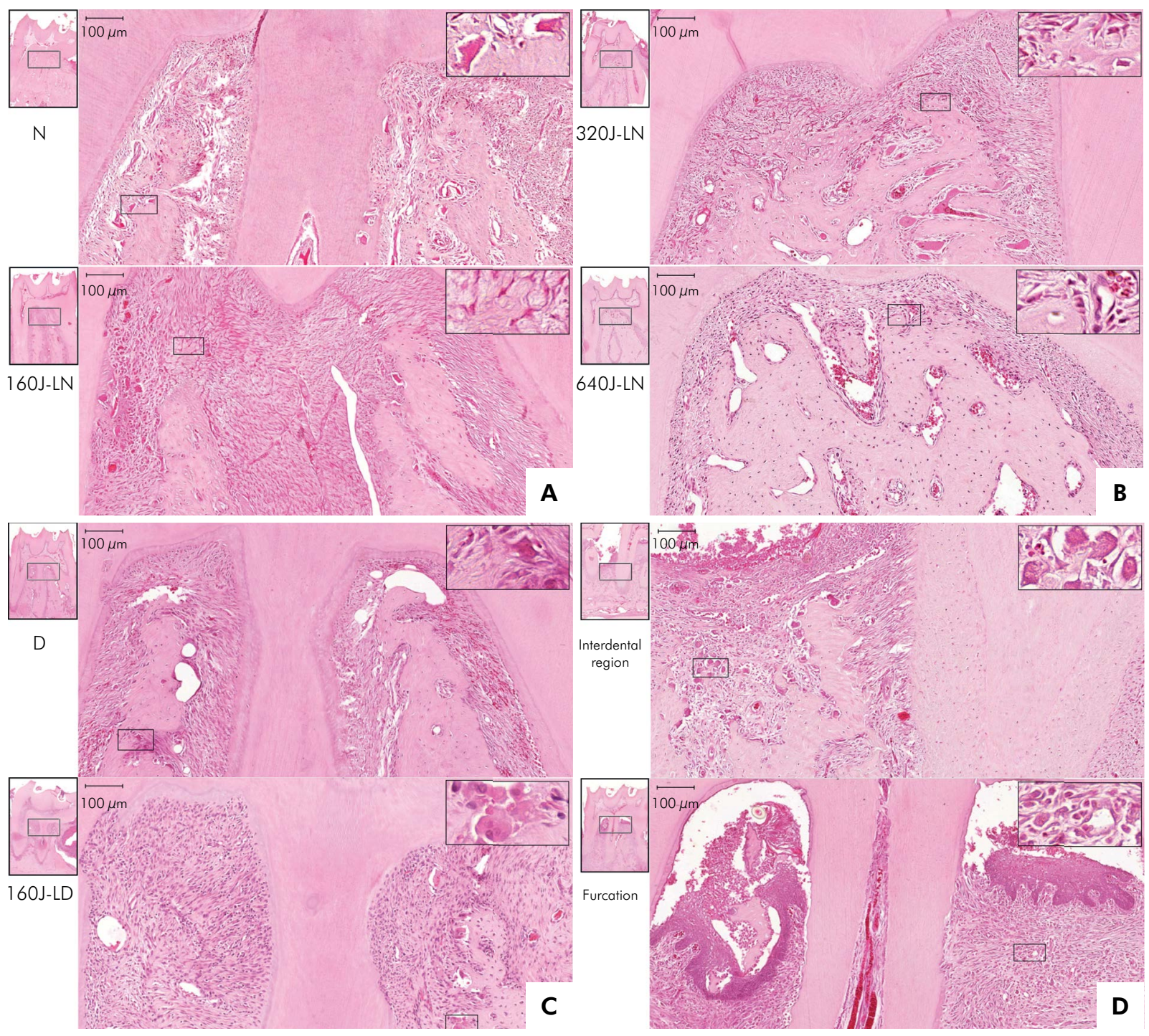

Figure 4. a) Photomicrographs showing furcation region of the orthodontically moved tooth. Intense resorption throughout the alveolar bone tissue and disorganization of the PDL tissue in the $\mathrm{N}$ and $160 \mathrm{~J}$-LN groups; and great amount of osteogenic connective tissue showing proliferation and differentiation of news osteoblast from osteogenic cells and presence of osteoid matrix, particularly in the $160 \mathrm{~J}$-LN group. (Hematoxylin and Eosin; Bars $=100 \mu \mathrm{m}$ ). b) Photomicrographs showing furcation region of the orthodontically moved tooth. Newly formed alveolar bone tissue from osteogenic connective tissue and PDL with intense cellularity and disorganized collagen fibers in the $320 \mathrm{~J}$-LN group; and well-preserved and mature alveolar bone tissue, well-organized PDL tissues, and rich vascularization in the $640 \mathrm{~J}$-LN group. (Hematoxylin and Eosin; Bars $=100 \mu \mathrm{m}$ ). c) Photomicrographs showing furcation region of the orthodontically moved tooth. Numerous blood capillaries, interstitial hemorrhage, and disorganized PDL in the D group; and intense osteoclastic activity eliciting accentuated alveolar bone loss in the $160 \mathrm{~J}$-DL group. (Hematoxylin and Eosin; Bars $=100 \mu \mathrm{m}$ ). d) 160 J-LD group. Photomicrographs showing the interdental and furcation regions. Interdental region (between the mandibular first and second molars): degradation of the PDL tissue and intense alveolar bone resorption; and furcation region: well-cellularized and wellvascularized connective tissue replacing the interdental septum region, and apical migration of the hyperplastic junctional epithelium toward the mandibular first molar furcation. (Hematoxylin and Eosin; Bars $=100 \mu \mathrm{m}$ ).

at the interdental region, especially in the $320 \mathrm{~J}-\mathrm{LN}$ group. In this same group, the osteogenic connective tissue was replaced by newly formed alveolar bone tissue. At the interdental and furcation regions of the $640 \mathrm{~J}-\mathrm{LN}$ group, the alveolar bone tissue showed mature and better preservation when compared with all the studied groups, and the PDL presented a better sustained effect due to the presence of well- 


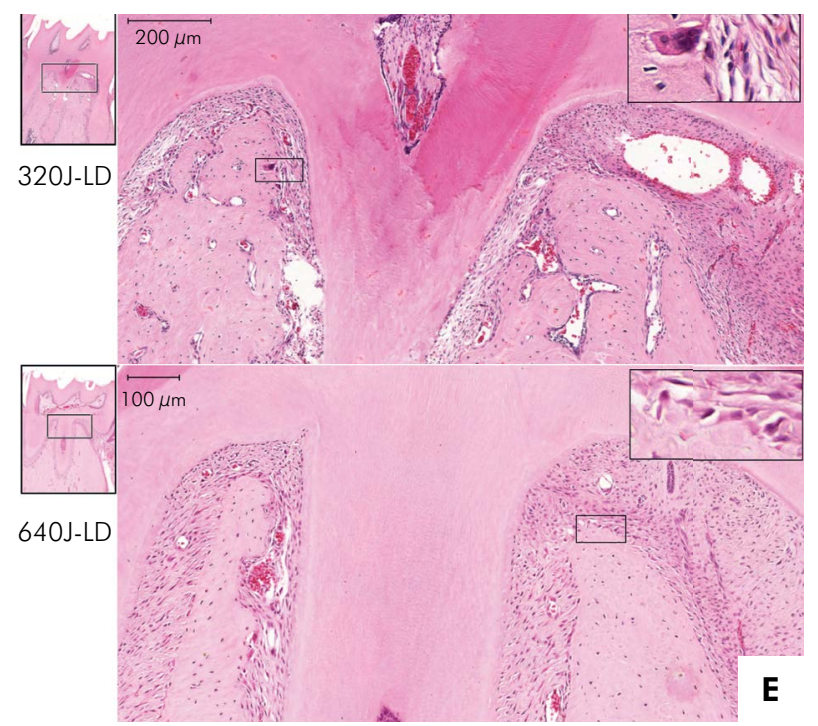

Figure 4. cont. e) Furcation region. Photomicrographs showing intense 320J-LD group showed well-cellularized and well-vascularized connective tissue and Interstitial hemorrhage; whereas the 640J-LD group presented well-organized collagen fibers and formed bone trabeculae with mature aspect, eliciting a better preservation of the alveolar bone microstructure among the diabetic groups. (Hematoxylin and Eosin; Bars $=200 \mu \mathrm{m}$ and $100 \mu \mathrm{m}$ ).

organized collagen fibers around the orthodontically moved tooth. In overview, the gingival epithelium and lamina propria showed normal aspect. Scarce infiltration of mononuclear inflammatory cells was evidenced at the lamina propria, particularly at the marginal gingival zone of the interdental region. It is important to highlight that rare tooth root resorptions were evidenced in the orthodontically moved tooth, in particular, in the $640 \mathrm{~J}-\mathrm{LN}$ group (Figure $4 \mathrm{a}$ and $\mathrm{b}$ ).

Concerning the diabetic groups, whether treated or not with laser irradiation, the D and $160 \mathrm{~J}-\mathrm{LD}$ groups revealed intense degradation of the PDL tissue and accentuated resorption of the laminate alveolar bone due to intense osteoclastic activity. The furcation and interdental regions (between the mandibular first and second molars), in particular, were replaced by well-cellularized and well-vascularized connective tissue, known as granulation tissue. In some specimens, the apical migration of hyperplastic junctional and gingival epithelium were evidenced toward the mandibular first molar furcation. Accentuated infiltration of polymorphonuclear and mononuclear inflammatory cells and extensive areas of alveolar bone loss were evidenced in both groups, especially in the $160 \mathrm{~J}-\mathrm{LD}$ group. The 640 J-LD group, followed by the 320 J-LD group, displayed numerous newly-formed alveolar bone trabeculae in the regions of furcation and interdental septum; in contrast, moderate to intense bone resorption of the alveolar crest were found in some specimens. At the mandibular first molar furcation region, the PDL showed large thickness, which was composed by well-organized collagen fibers, well-cellularized connective tissue, and mild mononuclear inflammatory cell infiltration. The vascularization was also evidenced in both groups (320 J-LD and $640 \mathrm{~J}-\mathrm{LD}$ groups); however, the 320 J-LD group showed greater exuberance. The newly formed bone trabeculae were evidenced at the furcation and interdental regions, eliciting better preservation of the alveolar bone microstructure, particularly in the $640 \mathrm{~J}-\mathrm{LD}$ groups. Finally, larger tooth root resorptions were found mainly in the $160 \mathrm{~J}-\mathrm{LD}$ group, followed by the D group, in comparison to other normoglycemic and diabetics groups (Figure 4c, d and e).

\section{Quantitative results}

To interpret the statistical results in the tables, the lowercase letters "abcdefgh" indicate the statistical significance in relation to the experimental groups; 
Effects of the photobiomodulation using different energy densities on the periodontal tissues under orthodontic force in rats with type 2 diabetes mellitus

where a group of these letters is found, the result for the group represented by the first letter is statistically significant in relation to the others (" $a$ ", N group; " $b$ ", 160 J-LN group; “c", 320 J-LN group; “d”, 640 J-LN group; "e", D group; "f", 160 J-LD group; “g”, 320 J-LD group; " $\mathrm{h}$ ", $640 \mathrm{~J}$-LD group). The statistical significance was considered at the level $\mathrm{p}<0.05, \mathrm{p}<0.01$, and $\mathrm{p}<0.001$.

\section{Radiographic parameter}

After 21 days, the diabetic groups exhibited higher the distance, between the cementoenamel junctions of the right mandibular first and second molars, when compared with the normoglycemic groups. The D group $(39.98 \pm 1.97)(p<0.001)$, the $640 \mathrm{~J}-\mathrm{LD}$ group $(35.47 \pm 4.56)(\mathrm{p}<0.001)$, and the 160
J-LD group $(34.84 \pm 6.01)(\mathrm{p}<0.001)$ displayed higher interdental distance, with an accentuated significant difference in relation to the $\mathrm{N}$ group $(21.13 \pm 1.19)$, the $160 \mathrm{~J}-\mathrm{LN}$ group (22.69 \pm 0.72$)$, the $320 \mathrm{~J}-\mathrm{LN}$ group (22.28 \pm 0.78$)$, and the $640 \mathrm{~J}-\mathrm{LN}$ group $(24.56 \pm 2.11)$. The 320 J-LD group $(29.82 \pm 1.73)$ presented the lowest linear measure among the diabetic groups; however, a statistically significant increase was shown in comparison with the $\mathrm{N}$ group $(\mathrm{p}<0.01)$, the 320 J-LN group ( $p<0.01)$, and the $160 \mathrm{~J}-\mathrm{LN}$ group $(\mathrm{p}<$ $0.05)$. Finally, there was no significant difference among the normoglycemic groups; even though, the 640 J-LN group $(24.56 \pm 2.11)$ has shown the highest distance in relation to the other normoglycemic groups (Table 1 and Figure 5).

Table 1. Values of the rates of orthodontic tooth movement represented by the interdental distance (pixels) between the cementoenamel junctions of the right mandibular first and second molars (Mean $\pm \mathrm{SD}$ ).

\begin{tabular}{|c|c|c|c|c|}
\hline Group & Mean \pm SD & SEM & Median & Min-Max \\
\hline$N(a)$ & $21.13 \pm 1.19$ & 0.53 & 21.42 & $19.99-22.85$ \\
\hline $160 \mathrm{~J}-\mathrm{LN}(\mathrm{b})$ & $22.69 \pm 0.72$ & 0.33 & 22.85 & $21.42-23.17$ \\
\hline $320 \mathrm{~J}-\mathrm{LN}(\mathrm{c})$ & $22.28 \pm 0.78$ & 0.35 & 22.85 & $21.42-22.85$ \\
\hline $640 \mathrm{~J}-\mathrm{LN}(\mathrm{d})$ & $24.56 \pm 2.11$ & 0.95 & 24.28 & $21.42-27.13$ \\
\hline $\mathrm{D}(\mathrm{e})$ & $39.98 \pm 1.97$ eabcdg $^{* * *}$ & 0.89 & 41.41 & $37.25-41.41$ \\
\hline 160J-LD (f) & $34.84 \pm 6.01$ fabcd $^{* * *}$ & 2.70 & 37.25 & $27.13-41.41$ \\
\hline $320 \mathrm{~J}-\mathrm{LD}(\mathrm{g})$ & $29.82 \pm 1.73 \mathrm{gac}^{* *}, \mathrm{gb}^{*}$ & 0.78 & 27.13 & $27.13-32.00$ \\
\hline 640J-LD (h) & $35.47 \pm 4.56$ habcd $^{* * *}$ & 2.04 & 35.70 & $28.56-41.41$ \\
\hline
\end{tabular}

$\mathrm{N}$ : normoglycemic rats; J-LN: J-laser-normoglycemic rats; D: diabetic rats; J-LD: J-laser-diabetic rats; SD: standard deviation; SEM: standard error of the mean. The value of 1 pixel is equal to $0.05 \mathrm{~mm}^{*} \mathrm{p}<0.05,{ }^{* *} \mathrm{p}<0.01$, and ${ }^{* * *} \mathrm{p}<0.001$.

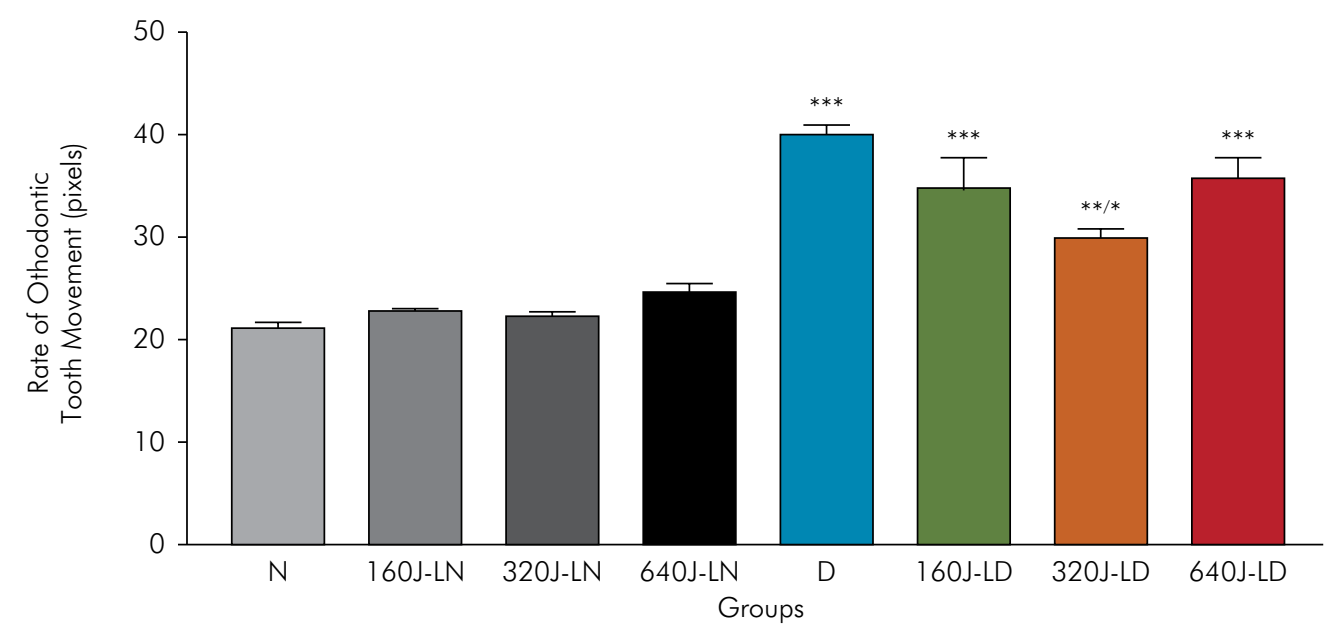

Figure 5. Quantitative analysis of the rates of orthodontic tooth movement as determined by radiographic parameter. Values are expressed as mean \pm standard deviation. 


\section{Immunohistochemical analysis}

The quantity of immune-positive osteocytes for OPN was significantly higher in the $640 \mathrm{~J}-\mathrm{LN}$ (13.62 $\pm 1.33 ; \mathrm{p}<0.05)$ and 640 J-LD $(14.72 \pm 0.82 ; \mathrm{p}<0.01)$ groups when compared with the $160 \mathrm{~J}-\mathrm{LD}$ group $(9.77 \pm 1.10)$, and D $(9.82 \pm 1.17)$ and $160 \mathrm{~J}-$ LD groups $(9.77 \pm 1.10)$, respectively (Figure 6). Furthermore, no statistical significance between the N, 160 J-LN, 320 J-LN and $640 \mathrm{~J}-\mathrm{LN}$ groups was found. This fact confirm that the photobiostimulation in the dosage of $640 \mathrm{~J} /$ $\mathrm{cm}^{2}$ strongly stimulated the alveolar bone formation when compared with the dosages of $160 \mathrm{~J} / \mathrm{cm}^{2}$ and $320 \mathrm{~J} / \mathrm{cm}^{2}$. Finally, the D and $160 \mathrm{~J}-\mathrm{LD}$ groups showed similar quantity of immune-positive osteocytes for OPN, and the lowest values when compared to the other groups. These findings could indicate the extensive alveolar bone loss in these same groups (Table 2 and Figure 7).

\section{Discussion}

In the current study, PBM-mediated biostimulatory effects were produced on the periodontal tissue, submitted to orthodontic tooth movement, in diabetic and normoglycemic rats, being similar to previous reports found in literature. ${ }^{9,10,11,15} \mathrm{~A}$ recent review by Kim et al. ${ }^{13}$ suggest that the PBM used in orthodontics improves permeability of cell wall and influx of $\mathrm{Ca}^{++}$, enhances ATP production and collagen synthesis, increases pro-inflammatory and anti-inflammatory cytokines, as well as activates several proteolytic enzymes essential for extracellular matrix remodeling,

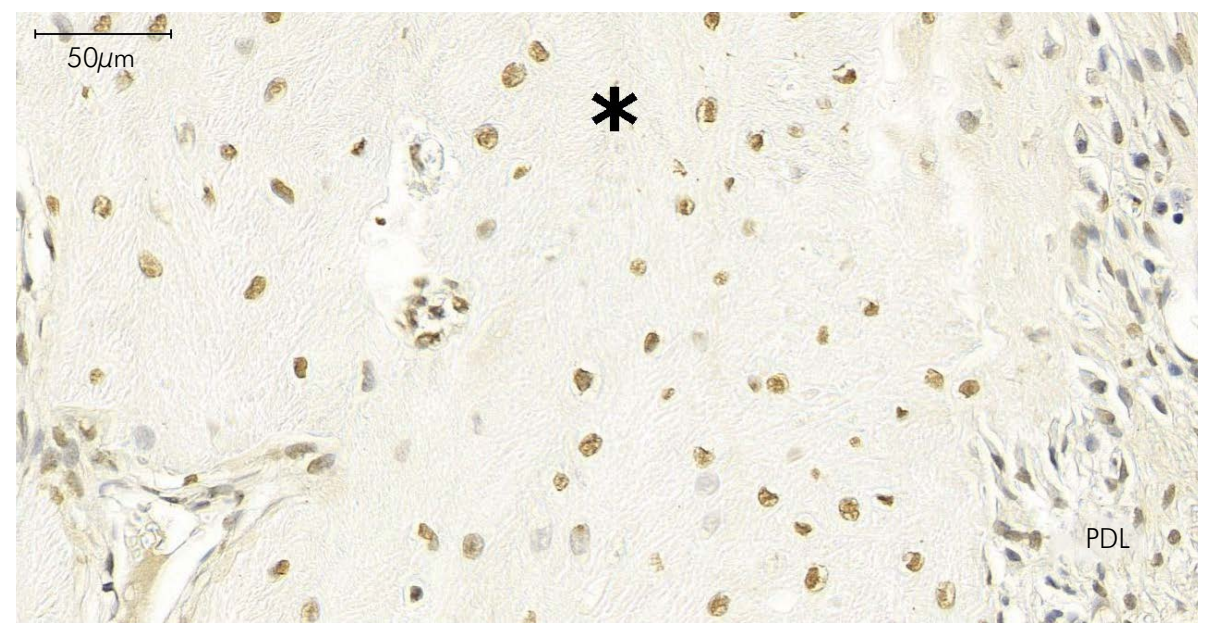

Figure 6. Representative immunohistochemical reactivity (arrows) for OPN in the 640J-LD group. Numerous immune-positive osteocytes located in the newly-formed alveolar bone tissue (asterisk) which is adjacent to the PDL (Immunohistochemical Staining; Bar $=50 \mu \mathrm{m}$ ).

Table 2. Quantity of immune-positive osteocytes for Osteopontin (mean \pm SD).

\begin{tabular}{lcccc}
\hline Group & Mean \pm SD & SEM & Median & Mix-Max \\
\hline N (a) & $13.56 \pm 0.60$ & 0.35 & 13.77 & $12.88-14.03$ \\
160J-LN (b) & $13.35 \pm 0.11$ & 0.06 & 13.40 & $13.23-13.43$ \\
\hline 320J-LN (c) & $13.36 \pm 2.54$ & 1.47 & 12.73 & $11.20-16.16$ \\
640J-LN (d) & $13.62 \pm 1.33 \mathrm{df*}$ & 0.77 & 13.10 & $12.63-15.13$ \\
\hline D (e) & $9.82 \pm 1.17$ & 0.68 & 9.27 & $9.03-11.17$ \\
160J-LD (f) & $9.77 \pm 1.10$ & 0.64 & 10.03 & $8.56-10.73$ \\
\hline 320J-LD (g) & $11.57 \pm 1.66$ & 0.95 & 10.93 & $10.33-13.45$ \\
640J-LD (h) & $14.72 \pm 0.82$ hef** $^{*}$ & 0.47 & 14.30 & $14.20-15.67$ \\
\hline
\end{tabular}

N: normoglycemic rats; J-LN: J-laser-normoglycemic rats; D: diabetic rats; J-LD: J-laser-diabetic rats; SD: standard deviation; SEM: standard error of the mean. ${ }^{*} p<0.05,{ }^{* *} p<0.01$, and ${ }^{* * *} p<0.001$. 
Effects of the photobiomodulation using different energy densities on the periodontal tissues under orthodontic force in rats with type 2 diabetes mellitus

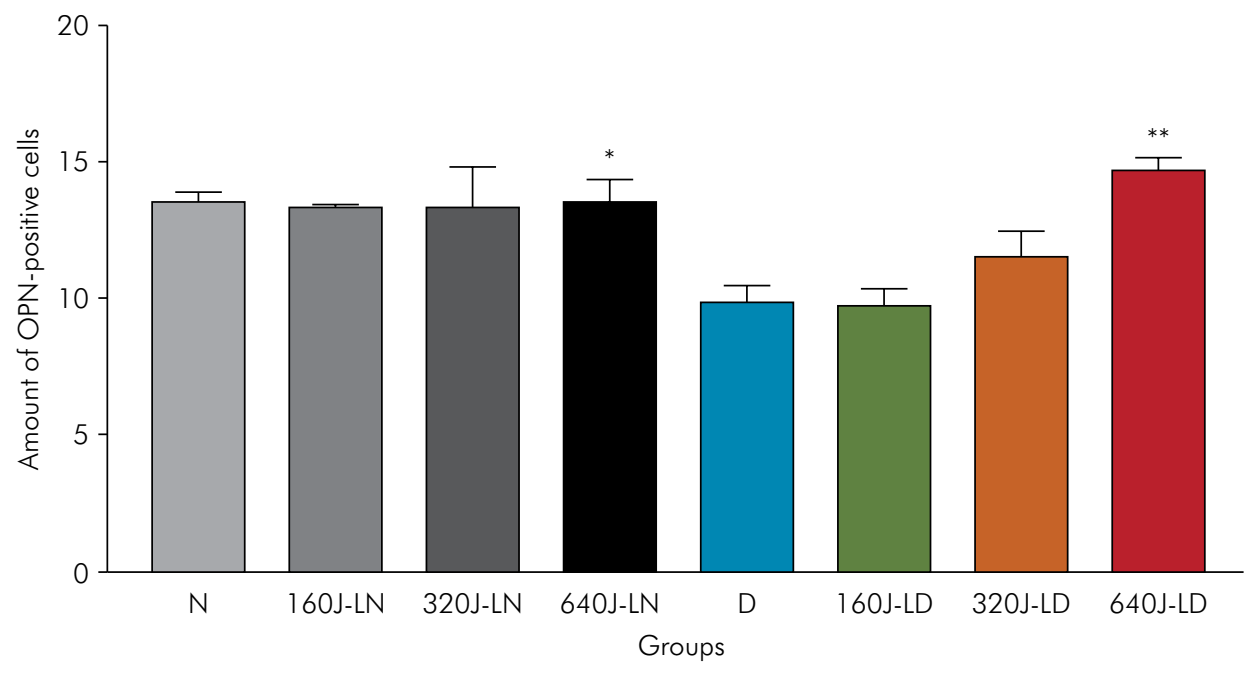

Figure 7. Quantitative analysis of osteopontin (OPN) expression in all studied groups. Values are expressed as mean \pm standard deviation.

favoring the periodontal tissue remodeling and reinforcing the tooth retention.

In this study, the irradiated rats showed low intensity of inflammatory process and intense vascularization on the PDL tissue, mainly those submitted to a higher dosage. These findings likely occurred due to the anti-inflammatory and angiogenic activities of laser irradiation. ${ }^{9,10,12,18}$ Among the energy densities, the dosage of $640 \mathrm{~J} / \mathrm{cm}^{2}$ showed more effective biostimulatory effects in relation to others, since there was an appropriate maintenance in the physiological periodontal homeostasis, in particular, in the uncontrolled diabetic rats; on the other hand, the dosage of $160 \mathrm{~J} / \mathrm{cm}^{2}$ showed the worst outcomes. It is important to highlight that, even though the $\mathrm{D}$ and $160 \mathrm{~J}-\mathrm{LD}$ groups had shown a great interdental distance between the first and second molars, intense alveolar bone resorptions, severe inflammatory activity, and accentuated degradation of the PDL tissue were evidenced in these groups, resulting in severe periodontitis. Most likely, this critical condition of the periodontium favored the dental mobility which was reinforced by the continuous orthodontic force. To explain the development of the periodontal disease in diabetes, several studies described that an increased wall thickness of small arteries, small veins, and capillaries is caused by the accumulation of anomalous glycoprotein, resulting in an irreversible non-enzymatic glycation processes.
This vascular alteration reduces the uptake of nutrients and oxygen by the periodontal tissues and leads to a high level of advanced glycation end products (AGEs). These products induce increased index values of oxidative stress in bone cells due to the absence of the counterbalancing effects of endogenous antioxidants. High tissue oxidative stress alters endothelial cell functions and elevates activity of matrix metalloproteinases, inducing the production of free radicals, increased vascular dysfunction, and cellular death. ${ }^{6,18,19,20}$ These molecular mechanisms could justify the severity of periodontal disease, found mainly in the D and 160 J-LD groups.

Considering these concepts, two interconnected processes were hypothesized to elucidate our histological outcomes. Firstly, a high concentration of AGEs could be present in the periodontal tissues, which may have been triggered by the elevated hyperglycaemia over a long period in the uncontrolled diabetic rats. This fact was reported in the works of Ponte et al. ${ }^{21}$ and Li et al. ${ }^{22}$ Additionally, these same investigators emphasized that significant biological dysfunctions of periodontal connective tissue may arise, making it more vulnerable to infections due to reduced leukocyte function and chemotaxis, decreased collagen synthesis, increased collagenase activity, and impaired bone remodeling. However, the measurement of immunohistochemical markers for AGE is necessary to validate this theory. Secondly, 
transient stress hyperglycaemia could be triggered by stressful situations, caused by the following clinical procedures: the handling of the animal during the general anesthesia procedure by various laser applications; and possible pain or discomfort experienced by the animals due to the use of the orthodontic appliance over a long period. According to Dungan et al., ${ }^{23}$ transient stress hyperglycaemia is caused by a highly complex interplay of counterregulatory hormones, including cathecholamines, norepinephrine, epinephrine, cortisol, $\beta$-endorphin, and growth hormone. These hormones reduce the insulin-mediated glucose transport, via GLUT-1 transporter, to body tissues and lead to an excessive hepatic glucose production, a resistance to insulin, an impaired disposal of non-oxidative glucose, and lypolysis, causing an increase in the blood glucose levels. These pathophysiological mechanisms result in a transient elevated hyperglycaemia. Thus, we consider that these processes could have intensified the periodontitis in the irradiated diabetic rat, mainly in the $160 \mathrm{~J}$-DL group. These facts imply that the dosage of $160 \mathrm{~J} / \mathrm{cm} 2$ produced an insufficient biostimulatory effect, resulting in little compensatory action on the impaired periodontal tissues in our study. However, in order to prove these correlations, more specific investigations are needs to assess the effects of stress hyperglycaemia on the periodontium undergoing orthodontic forces.

A further relevant histological feature was the intense formation of alveolar bone tissue in the 640 J-LN and 640 J-LD groups, which was proven by the great quantity of OPN-positive osteocytes. Among the diabetic groups, the $640 \mathrm{~J}-\mathrm{LD}$ group showed large interdental distance and, concomitantly, a better preservation of the periodontal tissues in comparison to other diabetic groups. The immunohistochemical results confirmed the histomorphological findings, since there was a high statistical significance in the number of OPN-positive osteocytes on the regions of furcation and mesial side of the interdental septum, mainly in the $640 \mathrm{~J}-\mathrm{LN}$ and $640 \mathrm{~J}$-LD groups.

Correlating the rate of tooth movement with the histological findings, in particular, in the diabetic groups, the application of the energy density of 640 $\mathrm{J} / \mathrm{cm}^{2}$ resulted in a large interdental distance, high quantity of OPN-positive osteocytes, and better integraty and maintenance of the physiological periodontal homeostasis. These findings confirm the better effectiveness of the PBM in this dosage in relation to the others. Additionally, although the dosage of $320 \mathrm{~J} / \mathrm{cm}^{2}$ have been suitable due to good formation of alveolar bone tissue confirmed by the high quantity of OPN-positive osteocytes, histologically, we found moderate alveolar bone resorption and inflammatory activity in some specimens. Thus, these outcomes reinforce the better efficacy of the dosage of $640 \mathrm{~J} / \mathrm{cm}^{2}$.

To consolidate our findings, other studies have also determined the OPN expression in osteocytes during the bone formation under mechanical stress in the calvarial suture in mice. Authors report that the presence of OPN is one of the positive factors for the bone formation in the mechanically stimulated environment. ${ }^{24,25}$ This noncollagenous bone matrix protein can also be expressed in some osteoblasts and bone lining cells at the resorption side in the early stage of experimental tooth movement. ${ }^{26,27}$ According to Tripuwabhrut et al., ${ }^{25}$ type I collagen (Col I), alkaline phosphatase (ALP), osteopontin (OPN) and osteocalcin $(\mathrm{OCN})$ are strongly expressed in the process of bone formation, induced by a continuous mechanical stress loading. Col 1 and APL are better evidenced at an early phase of cell differentiation, and OPN and OCN in the mineralisation phase.

With respect to the loss of tooth structures, the irradiated normoglycemic and irradiated diabetic rats, especially those that received a dosage of 640 $\mathrm{J} / \mathrm{cm}^{2}$, showed fewer areas of tooth root resorption in comparison to the others; on the other hand, the irradiated-diabetic rats with a dosage of $160 \mathrm{~J} /$ $\mathrm{cm}^{2}$, followed by the no-irradiated diabetic rats, presented greater resorptions. Previous researches described that the PBM, associated or not with osteoinductive biomaterials, may significantly reduce root resorptions. ${ }^{9,13,15}$ Although no osteopromotive material have been analyzed in our study, we hypothesize that the PBM using the dosage of 640 $\mathrm{J} / \mathrm{cm}^{2}$ could promote the inhibition of tooth root resorption processes; however, more investigations must be performed to better understanding of this histomorphological finding. 
Effects of the photobiomodulation using different energy densities on the periodontal tissues under orthodontic force in rats with type 2 diabetes mellitus

Considering the undertanting about the systemic and oral complications of diabetes mellitus, particularly the grave periodontitis, and the several benefits of the PBM on the periodontal tissues by the dental practitioners, we can highlight that the use of PBM with an apropriate energy density could be recommented as a important coadjuvant treatment in Orthodontics, mainly in cases of uncontrolled diabetic patients. Its effective biostimulatory actions on the periodontium may lead to more secure tooth movement due to maintenance and integrity of the supporting microstructures of the teeth, resulting in control over periodontal disease and, as a consequence, in improving of the systemic complications of diabetes.

\section{Conclusions}

The photobiomodulation, using the energy density of $640 \mathrm{~J} / \mathrm{cm}^{2}$, provided the best maintenance and integrity of the periodontal tissue microarchitecture

\section{References}

1. Ship JA. Diabetes and oral health: an overview. J Am Dent Assoc. 2003 Oct;134(Spec No):4S-10S. https://doi.org/10.14219/jada.archive.2003.0367

2. Braga SM, Taddei SR, Andrade I Jr, Queiroz-Junior CM, Garlet GP, Repeke CE, et al. Effect of diabetes on orthodontic tooth movement in a mouse model. Eur J Oral Sci. 2011 Feb;119(1):7-14. https://doi.org/10.1111/j.1600-0722.2010.00793.x

3. Vieira EM, Ueno CS, Valva VN, Goulart M, Nogueira TO, Gomes MF. Bone regeneration in cranioplasty and clinical complications in rabbits with alloxan-induced diabetes. Braz Oral Res. 2008 Apr-Jun;22(2):184-91. https://doi.org/10.1590/S1806-83242008000200015

4. Villarino ME, Lewicki M, Ubios AM. Bone response to orthodontic forces in diabetic Wistar rats. Am J Orthod Dentofacial Orthop. 2011 Apr;139(4 Suppl):S76-82. https://doi.org/10.1016/i.ajodo.2010.06.021

5. Brown ML, Yukata K, Farnsworth CW, Chen DG, Awad H, Hilton MJ, et al. Delayed fracture healing and increased callus adiposity in a C57BL/6J murine model of obesity-associated type 2 diabetes mellitus. PLoS One. 2014 Jun;9(6):e99656. https://doi.org/10.1371/journal.pone.0099656

6. Gomes MF, Valva VN, Vieira EM, Giannasi LC, Salgado MA, Vilela-Goulart MG. Homogenous demineralized dentin matrix and platelet-rich plasma for bone tissue engineering in under continuous orthodontic force when compared with the other dosages, mainly in the uncontrolled diabetic rats. The interdental distance was greater in the $\mathrm{D}$ and $160 \mathrm{~J}-\mathrm{LD}$ groups due to presence of severe periodontitis caused by diabetes plus the mechanical stress generated by continuous orthodontic forces, implying, thus, an insufficient biostimulatory effect for the dosage of $160 \mathrm{~J} / \mathrm{cm}^{2}$.

\section{Acknowledgments}

This research was supported by FAPESP (São Paulo Research Foundation, grant number: 2010/50500-1). The authors thank Valeria Adriano Vieira (FAPESP/ grant number: 2010/18117-3) for assisting in the laboratorial procedures, Johnson \& Johnson MD\&D Latin America Manufacturing Company Brazil for the donation of OneTouch Ultra Blood test strips and machine (LifeScan, Johson \& Johnson), and Danielle Hersey da Silva of the Brazil-United States Cultural Institute for the linguistic consultancy.

cranioplasty of diabetic rabbits: biochemical, radiographic, and histological analysis. Int J Oral Maxillofac Surg. 2016 Feb;45(2):255-66. https://doi.org/10.1016/j.ijom.2015.09.009

7. Hamada Y, Kitazawa S, Kitazawa R, Fujii H, Kasuga M, Fukagawa M. Histomorphometric analysis of diabetic osteopenia in streptozotocin-induced diabetic mice: a possible role of oxidative stress. Bone. 2007 May;40(5):1408-14. https://doi.org/10.1016/i.bone.2006.12.057

8. Hamada Y, Fujii H, Fukagawa M. Role of oxidative stress in diabetic bone disorder. Bone. 2009 Jul;45 Suppl 1:S35-8. https://doi.org/10.1016/i.bone.2009.02.004

9. Seifi M, Shafeei HA, Daneshdoost S, Mir M. Effects of two types of low-level laser wave lengths (850 and $630 \mathrm{~nm}$ ) on the orthodontic tooth movements in rabbits. Lasers Med Sci. 2007 Nov;22(4):261-4. https://doi.org/10.1007/s10103-007-0447-9

10. Habib FA, Gama SK, Ramalho LM, Cangussú MC, Santos Neto FP, Lacerda JA, et al. Laser-induced alveolar bone changes during orthodontic movement: a histological study on rodents. Photomed Laser Surg. 2010 Dec;28(6):823-30. https://doi.org/10.1089/pho.2009.2732

11. Altan BA, Sokucu O, Ozkut MM, Inan S. Metrical and histological investigation of the effects of low-level laser therapy on orthodontic tooth movement. Lasers Med Sci. 2012 Jan;27(1):131-40. https://doi.org/10.1007/s10103-010-0853-2 
12. Artés-Ribas M, Arnabat-Dominguez J, Puigdollers A. Analgesic effect of a low-level laser therapy $(830 \mathrm{~nm})$ in early orthodontic treatment. Lasers Med Sci. 2013 Jan;28(1):335-41. https://doi.org/10.1007/s10103-012-1135-y

13. Kim SJ, Kang YG, Park JH, Kim EC, Park YG. Effects of low-intensity laser therapy on periodontal tissue remodeling during relapse and retention of orthodontically moved teeth. Lasers Med Sci. 2013 Jan;28(1):325-33. https://doi.org/10.1007/s10103-012-1146-8

14. Yassaei S, Fekrazad R, Shahraki N. Effect of low level laser therapy on orthodontic tooth movement: a review article. J Dent (Tehran). 2013 May; 10(3):264-72.

15. Carvalho-Lobato P, Garcia VJ, Kasem K, Ustrell-Torrent JM, Tallón-Walton V, Manzanares-Céspedes MC.

Tooth movement in orthodontic treatment with low-level laser therapy: a systematic review of human and animal studies. Photomed Laser Surg. 2014 May;32(5):302-9. https://doi.org/10.1089/pho.2012.3439

16. Shirazi M, Ahmad Akhoundi MS, Javadi E, Kamali A, Motahhari P, Rashidpour M, et al. The effects of diode laser $(660 \mathrm{~nm})$ on the rate of tooth movements: an animal study. Lasers Med Sci. 2015 Feb;30(2):713-8. https://doi.org/10.1007/s10103-013-1407-1

17. Gomes MF, Goulart MGV, Giannasi LC, Hiraoka CM, Melo GFS, Sousa AGV et al. Effects of the GaAlAs diode laser $780 \mathrm{~nm}$ photobiomodulation on the periodontal tissues during orthodontic tooth movement in diabetes rats: histomorphological and immunohistochemical analysis. Lasers Med Sci. 2017;32(7):1479-87. https://doi.org/10.1007/s10103-017-2268-9

18. de Almeida JM, Theodoro LH, Bosco AF, Nagata MJ, Bonfante S, Garcia VG. Treatment of experimental periodontal disease by photodynamic therapy in rats with diabetes. J Periodontol. 2008 Nov;79(11):2156-65. https://doi.org/10.1902/jop.2008.080103
19. Abbass MM, Korany NS, Salama AH, Dmytryk JJ, SafiejkoMroczka B. The relationship between receptor for advanced glycation end products expression and the severity of periodontal disease in the gingiva of diabetic and non diabetic periodontitis patients. Arch Oral Biol. 2012 Oct;57(10):1342-54. https://doi.org/10.1016/i.archoralbio.2012.06.007

20. Stanko P, Izakovicova Holla L. Bidirectional association between diabetes mellitus and inflammatory periodontal disease: a review. Biomed Pap Med Fac Univ Palacky Olomouc Czech Repub. 2014;158(1):35-8. https:/doi.org/10.5507/bp.2014.005

21. Ponte E, Tabaj D, Maglione M, Melato M. Diabetes mellitus and oral disease. Acta Diabetol. 2001;38(2):57-62. https://doi.org/10.1007/s005920170014

22. Li X, Zhang L, Wang N, Feng X, Bi L. Periodontal ligament remodeling and alveolar bone resorption during orthodontic tooth movement in rats with diabetes. Diabetes Technol Ther. 2010 Jan;12(1):65-73. https://doi.org/10.1089/dia.2009.0085

23. Dungan KM, Braithwaite SS, Preiser JC. Stress hyperglycaemia. Lancet. 2009;373(9677):1798-807. https://doi.org/10.1016/S0140-6736(09)60553-5

24. Morinobu M, Ishijima M, Rittling SR, Tsuji K, Yamamoto H, Nifuji A, et al. Osteopontin expression in osteoblasts and osteocytes during bone formation under mechanical stress in the calvarial suture in vivo. J Bone Miner Res. 2003 Sep;18(9):1706-15. https://doi.org/10.1359/ibmr.2003.18.9.1706

25. Tripuwabhrut P, Mustafa M, Gierde CG, Brudvik P, Mustafa K. Effect of compressive force on human osteoblast-like cells and bone remodelling: an in vitro study. Arch Oral Biol. 2013 Jul;58(7):826-36. https://doi.org/10.1016/i.archoralbio.2013.01.004

26. Terai K, Takano-Yamamoto T, Ohba Y, Hiura K, Sugimoto M, Sato $M$, et al. Role of osteopontin in bone remodeling caused by mechanical stress. J Bone Miner Res. 1999 Jun;14(6):839-49. https://doi.org/10.1359/jbmr.1999.14.6.839

27. Fujihara S, Yokozeki M, Oba Y, Higashibata Y, Nomura $S$, Moriyama K. Function and regulation of osteopontin in response to mechanical stress. J Bone Miner Res. 2006 Jun;21(6):956-64. https://doi.org/10.1359/jbmr.060315 